Operator-related aspects in endodontic malpractice claims in Finland

\author{
Vehkalahti, Miira M.
}

2017-04

Vehkalahti , M M \& Swanljung , O 2017 , ' Operator-related aspects in endodontic malpractice claims in Finland ', Acta Odontologica Scandinavica, vol. 75 , no. 3 , pp. 155-160 . https://doi.org/10.1080/00016357.2016.1272000

http://hdl.handle.net/10138/310307

https://doi.org/10.1080/00016357.2016.1272000

unspecified

acceptedVersion

Downloaded from Helda, University of Helsinki institutional repository.

This is an electronic reprint of the original article.

This reprint may differ from the original in pagination and typographic detail.

Please cite the original version. 


\section{Operator-related aspects in endodontic malpractice claims in Finland}

Miira M Vehkalahti ${ }^{\mathrm{a}}$ and Outi Swanljung ${ }^{\mathrm{b}}$

${ }^{a}$ Department of Oral and Maxillofacial Diseases, Faculty of Medicine, University of Helsinki, Helsinki, Finland

${ }^{\mathrm{b}}$ The Patient Insurance Centre, Helsinki, Finland

Running head: Endodontic malpractice claims in Finland

Corresponding author:

Miira M Vehkalahti, P.O.Box 41, Department of Oral and Maxillofacial Diseases,

Faculty of Medicine, University of Helsinki, FI-00014 Helsinki, Finland

E-mail: miira.vehkalahti@helsinki.fi ORCID ID: 0000-0002-6319-854X 


\begin{abstract}
Objective: We analyzed operator-related differences in endodontic malpractice claims in Finland. Materials and methods: Data comprised the endodontic malpractice claims handled at the Patient Insurance Centre (PIC) in 2002-2006 and 2011-2013. Two dental advisors at the PIC scrutinized the original documents of the cases $(n=1271)$.

The case-related information included patient's age and gender, type of tooth, presence of radiographs, and methods of instrumentation and apex location. As injuries, we recorded broken instrument, perforation, injuries due to root canal irrigants/medicaments, and miscellaneous injuries. We categorized the injuries according to the PIC decisions as avoidable, unavoidable, or no injury. Operator-related information included dentist's age, gender, specialization, and service sector. We assessed level of patient documentation as adequate, moderate, or poor. Chi-squared tests, t-tests, and logistic regression modeling served in statistical analyses.
\end{abstract}

Results: Patients' mean age was 44.7 (range 8 -85) years, and $71 \%$ were women. The private sector constituted 54\% of claim cases. Younger patients, female dentists, and general practitioners predominated in the public sector. We found no sector differences in patients' gender, dentists' age, or type of injured tooth. PIC advisors confirmed no injury in $24 \%$ of claim cases; the advisors considered $65 \%$ of injury cases $(n=970)$ as avoidable and $35 \%$ as unavoidable. We found no operator-related differences in these figures. Working methods differed by operator's age and gender. Adequate patient documentation predominated in the public sector and among female, younger, or specialized dentists.

Conclusions: Operator-related factors had no impact on endodontic malpractice claims.

Key Words: Patient insurance; dental malpractice; indemnity of malpractice claims; service sector; avoidable injuries 


\section{Introduction}

Endodontic injuries form a considerable proportion of malpractice claims in dentistry [1-7]. By following good clinical practice, dentists should, however, be able to avoid patient injuries in endodontic treatments. To help dentists with the challenges faced in endodontics, several guidelines are available [8-11], the most recent published in Finland in June 2016 [12].

Typical injuries in endodontic malpractice are perforation and a broken instrument [6]. A report from Denmark analyzed endodontic malpractice claims and found that perforations accounted for $10 \%$ of 'technical complications' [4], whereas an analysis on endodontic injuries in Israel reported errors in instrumentation for half of the cases and in opening canals for $37 \%$ [5]. In addition, root canal irrigants and medicaments can cause injuries when ending up outside the root canal [13].

To diminish failures in healthcare, Nordic countries have fairly similar systems that follow the 'No Blame / No Fault' rule. In Finland, the Patient Insurance Centre (PIC) handles patient healthcare claims according to The Patient Injury Act of 1987 and decides about the indemnity of a financial compensation for cases where the injury could have been avoided by following good clinical practice. Patients from both the private and public sector can submit a claim easily and free of charge using forms available at service points and online. PIC receives on average about 7600 claims annually; in 2013-2015, endodontics was the most common clinical discipline on PIC's Top Ten list of all health care claims [14].

The PIC official statistics gives no detailed description of the injuries. A recent paper, based on the PIC data, reports the annual number of dentistry-related claims to be around 700 , endodontics constituting 29\% [15]. Another study from Finland analyzed health authority registers about the claims made against healthcare professionals and reported that around $7 \%$ of cases were related to endodontics and that male dentists or those who were general practitioners or older than 40 years were more subject to complaints regarding their clinical performance, but no differences existed between the two service sectors: private and public [16]. 
In this study, we analyzed the malpractice claims related to endodontics to determine whether differences exist according to the service sector and other operator-related characteristics.

\section{Material and methods}

\section{Oral health services in Finland}

In Finland, $57 \%$ of the dentists work in the public sector and $43 \%$ in the private sector; the mean age of employed dentists $(n=4400)$ is 47.9 years, $71 \%$ are female, and $7 \%$ are of foreign origin [17]. The public sector has the responsibility of providing dental care for children below 18 years of age free of charge. In both sectors, services are open to the whole population; patients are free to decide where to go for dental care. The fees in the public sector are subsidized and notably smaller than those in the private sector, despite private sector patients receiving a partial reimbursement from the Social Insurance Institute for dental care, except for prosthodontic and orthodontic treatments.

\section{Ethical consideration}

Our study is based on decisions made by the PIC on endodontic malpractice claims in 2002-2006 and 2011-2013. The PIC, together with the Ministry of Social Affairs and Health, approved the study protocol. To further ensure fulfillment of ethics criteria, running numbers were the only identifiers for the cases in the database.

\section{Data collection}

The target cases were all endodontic malpractice claims $(n=1322)$ handled at the PIC in 2002-2006 and 2011-2013. Two dental advisors at the PIC, both specialists in endodontics, scrutinized the official documents of the endodontic malpractice claims and recorded the raw data on a computerized platform created for this purpose. Later, we tested the data for logicality and possible errors and corrected any mistakes on the basis of original patient documents, re-scrutinized by one of the authors (OS). We excluded 51 incomplete cases due to missing identification of the 
tooth $(n=37)$, double claims for the same treatment $(n=3)$, and withdrawn cases $(n=11)$. A total of 1271 cases remained for analyses.

\section{Data on the cases}

The data included patients' gender and age, defined as years from birth to the time of the injury, and the service sector where the treatment took place. The teeth in question were categorized as anteriors (incisors and canines), premolars, or molars. Information gathered from the patient documents included the presence of radiographs, method of instrumentation (manual or engine-driven), and use of an electronic apex locator. The injuries recorded were perforation of the root canal or pulp chamber, a broken root canal instrument, injuries due to root canal irrigants and medicaments, and miscellaneous injuries such as under/overfilling, wrong diagnosis, and unnecessary treatment. In addition, the dental advisors assessed the level of the original patient documentation into three categories: adequate, moderate, and poor. Adequate documentation included dental and pulpal diagnosis, method of apex location and instrumentation, and data on working length, canal irrigants and medicaments, filling material and pre- and postoperative radiographs. Moderate documentation included pulpal diagnosis and information about apex location, canal irrigants and medicaments, and postoperative radiographs. Poor documentation included medicaments, working length, and radiographs; missing documentation was included in this category as well. As part of the claim handling process the PIC advisors, all being experienced clinicians, assess each claim in detail and make a suggestion about whether or not the incident could have been avoided. We categorized the injuries according to the final PIC decisions about the claims as avoidable injury, unavoidable injury, and no injury. The first category refers to injuries that could have been avoided had the operator followed good clinical practice, whereas unavoidable injuries refer to the normal risks related to healthcare.

\section{Data on the operators}

The patient documents included only the operator's name and working sector. We used public sources to find additional background data on the operators. The yearbooks of the 
Finnish dentists gave reliable information, but not for those dentists who recently graduated or were only temporarily working in Finland. The inquiry system of the National Supervisory Authority for Welfare and Health (Valvira) reveals the name, year of birth, and professional details of all healthcare workers holding a current license to practice. Unfortunately, the service does not provide the operator's gender. For Finnish dentists, their given name indicated their gender clearly enough, but not so for all dentists of foreign background. Age and gender remained unknown for short-term operators who had returned to their country of origin and for those who had otherwise lost their license to practice as a dentist. In total, data on operator's gender were missing for 6 cases and on age for 51 cases.

\section{Statistical methods}

To evaluate differences between the groups, we used Chi-squared tests for frequencies and t-tests for mean values. Further, we analyzed the role of operator-related factors in the occurrence of avoidable injuries. We applied logistic regression modeling and calculated odds ratios (ORs) and their $95 \%$ confidence intervals (95\% CIs). Analyses were performed with the software Survo MM version 3.4.1 (http://www.survo.fi/mm/english.html).

\section{Results}

Patients' age ranged from 8 to 85 years, and the vast majority were women. The private sector accounted for $54 \%$ of the malpractice claims, $56 \%$ in $2002-2006$ and $51 \%$ in 2011 $2013(\mathrm{p}=0.061)$. Table 1 shows a comparison between the sectors with regard to patients, dentists, and the teeth in question. Younger patients, female dentists, and general practitioners predominated in the public sector. We found no sector differences in patients' gender, dentists' age, or type of tooth. [Table 1 near here]

Table 2 shows various aspects of the treatment process in endodontic malpractice claims according to operators' characteristics. Root canal instrumentation had been manual in $61 \%$ 
of the cases; engine-driven instrumentation had been used more frequently by male than female dentists $(34 \%$ vs. $28 \% ; \mathrm{p}=0.026)$ and by younger dentists. A preoperative radiograph was available for $62 \%$ of cases, and no operator-related differences emerged. The method for apex location was working length radiograph in $43 \%$ of cases. For $37 \%$ of cases, the method had gone undocumented, more frequently by male (43\%) or older $(45 \%)$ dentists. [Table 2 near here]

Patient documentation was adequate in $50 \%$, moderate in $32 \%$, and poor in $18 \%$ of cases (Table 2). The operator-related differences were statistically highly significant; adequate documentation was more frequent in the public sector, by female dentists, and by the youngest dentists. Figure 1 shows that $77 \%$ of dentists under 30 years of age had provided adequate patient documentation, around $40 \%$ of 50 - to 59 -year-olds, and $25 \%$ of those aged 60 years and older. [Figure 1 near here]

The dental advisors found one injury in $73 \%$ and $2-3$ injuries in $3 \%$ of cases; $24 \%$ of the claims had no injury. The advisors confirmed a broken instrument in $24 \%$ and perforation in $22 \%$ of submitted claims; in $5 \%$ of cases the injury was related to root canal irrigants/medicaments; $27 \%$ were miscellaneous injuries (Table 3). We found no operator-related differences in occurrence of injury types. [Table 3 near here]

The advisors verified injuries in a total of 970 claims, deeming $65 \%$ of these as avoidable and $35 \%$ as unavoidable. We analyzed the role of operator-related factors in the occurrence of avoidable injuries by means of a logistic regression model (Table 4). Dentist's age was the only operator-related factor reaching statistical significance $(\mathrm{OR}=1.02 ; \mathrm{p}=0.007)$. Service sector and dentists' gender and specialization remained insignificant terms in the model after controlling for patient's age. Dentist's age was missing in 51 cases; to enroll all cases in the analyses, we fitted a model without this factor and this model (not shown) produced virtually the same estimates and odds ratios seen in Table 4. [Table 4 near here] 


\section{Discussion}

We found no operator-related differences in scrutinized endodontic malpractice claims or verified injuries. This indicates that adverse events occur in the entire profession, not only in a narrow and skewed segment of it. The majority (65\%) of verified injuries were judged avoidable had the operator followed good clinical practice. Our finding is in line with a study based on the Finnish health authority claim registers reporting $65 \%$ of patient safety incidents in dental and oral treatments as being 'possibly preventable' [16]. The cases assessed to be avoidable injuries may reflect dentists' deficient knowledge of the normal variety in root canal anatomy and their inadequate training in the use of a new technique. Therefore, ways to ensure dentists' know-how in endodontics should be sought after graduation and over the entire clinical career.

The curriculum in dentistry gives basic level of skills and guides referring to specialists when needed. However, frequent referrals of endodontic cases can be an unrealistic option in Finland since only about $1.3 \%$ of dentists are specialized in endodontics. In the UK, where the corresponding proportion is only $0.67 \%$, new concepts have been piloted for developing dentists with enhanced skills via training and support at the primary care units [18]. Analogous attempts may be applicable in larger clinics, public or private, to create a chain of support for general practitioners in the form of guided working, easy consultation, and referral as needed. Such support would be of great value to dentists, who often feel like they are 'working in the dark' because of the complexity of root canal treatment [19].

Both administration and operators in oral healthcare services have recently become more aware of the importance of identifying situations leading to adverse events. Consequently, new tools are available to avoid or diminish such events. The conceptual framework for proper discussions on patient safety has been developed by the World Health Organization [20], but also locally, e.g. in Finland [21]. A recent review concludes that 'the only interventions in dentistry that reduce or minimize adverse events are surgical safety checklists [22]. Other papers suggest monitoring patient records to identify triggers for adverse events [23], but also patient complaints 
are relatively reliable safety risk indicators [24]. Regular debriefing of and discussion about adverse events at clinics could lead to improvements in patient safety. Recently, a paper from the UK gave practical suggestions on such attempts to be applied in oral healthcare services [25].

Patients' increasing awareness about the possibility of submitting a malpractice claim has been seen as a continuous increase in the numbers of claims handled by the PIC and in compensation paid for injuries [14]. In one of three endodontic claims, the PIC advisors found no injury; such cases nevertheless reflect the patient's dissatisfaction with treatment. In addition, patient complaints serve as an indicator of a lack of quality or safety [16,24] and should thus be discussed seriously by the operator and the whole team.

With regard to the process of root canal treatment, an interesting finding was the notable differences in methods of instrumentation and apex location according to the dentist's gender, age, and specialization. Manual instrumentation and radiograph-based apex location predominated among female dentists or among unspecialized or older dentists; almost half of the male dentists and older dentists left the method undocumented. The most prominent operatorrelated differences occurred, however, in patient documentation, which was adequate mostly in cases treated in the public sector or by female, younger, or specialized dentists.

A few reports have shown that female dentists may emphasize preventive and conservative treatments and be slower to adopt new technical equipment in day-to-day practice. In Denmark, female dentists used electronic devices less frequently and performed fewer root canal treatments than their male colleagues [26]. Regarding instrumentation, our results confirm their finding of a gender difference. Finland has a long history of women serving as the majority in the dental profession and in the public sector. Two earlier reports from Finland have shown that the quality of root canal treatment is better for younger dentists than for their older peers [27] and that female dentists and younger dentists tend to record more information in patient documents [28]. Our findings confirm these results. 
Our large material includes all endodontic malpractice claims handled by the PIC over an 8-year period, thus reliably describing the situation in Finland in the 2000s. Indemnity of the 2002-2006 claims had been partly analyzed earlier [29]. Since the role of public sector in serving adult patients has slightly expanded [30], we updated our data by adding all endodontic claims handled in 2011-2013. However, we found no difference between the data sets in numbers of claims by sector $(\mathrm{p}=0.061)$. Comparison with the official data of the dental workforce in Finland reveals that the private dentists here formed a larger proportion than they are in actuality (54\% vs. 43\%); this is, however, understandable because the private sector provides services mainly to adults. A similar comparison of dentists' gender shows an underrepresentation of female dentists in our study ( $62 \%$ vs. $71 \%$ ), most likely due to the predominance of cases from the private sector, where more dentists are male.

The experienced PIC advisors assessed the claims, but the scrutiny relied on the patient documents and related information required from the operator. Since our results revealed a large variety in the quality of documentation, the amount of data available differed from case to case. This can be seen as a limitation of the study.

\section{Conclusions}

Operator-related factors had no impact on endodontic malpractice claims. Two of three verified patient injuries could have been avoided by following good clinical practice.

\section{Acknowledgments}

The authors thank Sirpa Pöyry, DDS, who assisted with inspection of the 2002-2006 cases, as well as Ville Lilja, MSc, and Mika Sirviö, MSc, who helped with data collection.

\section{Disclosure statement}

The authors report no conflicts of interest. 


\section{References}

1. Cohen S, Schwartz S. Endodontic Complications and the Law. J Endod 1987;13:191-197.

2. Milgrom P, Fiset L, Whitney C, et al. Malpractice claims during 1988-1992: a national survey of dentists. J Am Dent Assoc 1994;125:462-469.

3. Hapcook CP Sr. Dental malpractice claims: percentages and procedures. J Am Dent Assoc 2006;137:1444-1445.

4. Bjørndal L, Reit C. Endodontic malpractice claims in Denmark 1995-2004. Int Endod J 2008;41:1059-1065.

5. Givol N, Rosen E, Taicher S, et al. Risk Management in Endodontics. J Endod 2010;36:982984.

6. Pinchi V, Pradella F, Gasparetto L, et al. Trends in endodontic claims in Italy. Int Dent $\mathbf{J}$ 2013;63:43-48

7. Kiani M, Sheikhazadi A. A five-year survey for dental malpractice claims in Tehran, Iran. J Forensic Leg Med 2009;16:76-82.

8. European Society of Endodontology. Quality guidelines for endodontic treatment: consensus report of the European Society of Endodontology. Int Endod J 2006;39:921-930. http://onlinelibrary.wiley.com/doi/10.1111/j.1365-2591.2006.01180.x/pdf

9. Swedish Council on Health Technology Assessment. Methods of Diagnosis and Treatment in Endodontics. A Systematic Review. SBU Report No: 203E. 2012 http://www.sbu.se/en/Published/Yellow/Methods-of-Diagnosis-and-Treatment-inEndodontics/

10. Evans GE, Bishop K, Renton T. Guidelines for Surgical Endodontics. The Royal College of Surgeons of England 2012. https://www.rcseng.ac.uk/fds/publications-clinicalguidelines/clinical_g uidelines/documents/surgical_endodontics_2012.pdf

11. American Association of Endodontists. Guide to Clinical Endodontics. 2013. http://www.nxtbook.com/nxtbooks/aae/guidetoclinicalendodontics5/ 
12. Finnish Dental Society Apollonia [Current Care Guideline: Endodontic treatment]. 2016. Finnish. http://www.kaypahoito.fi/web/kh/suositukset/suositus?id=hoi50110

13. Hülsmann M, Hahn W. Complications during root canal irrigation literature review and case reports. Int Endod J 2000;33:186-193.

14. Patient Insurance Centre, Statistics. 2016. http://www.pvk.fi/en/statistics/

15. Karhunen S, Virtanen JI. Dental treatment injuries in the Finnish Patient Insurance Centre in 2000-2011. Acta Odontol Scand 2016;74:236-240. DOI: 10.3109/00016357.2015.1103898

16. Hiivala N, Mussalo-Rauhamaa H, Tefke H-L, et al. An analysis of dental patient safety incidents in a patient complaint and healthcare supervisory database in Finland. Acta Odontol Scand 2016;74:81-89. DOI: 10.3109/00016357.2015.1042040

17. National Institute for Health and Welfare. Health care and social welfare personnel 2013. Official Statistics of Finland, Statistical Report 26/2015. https://www.julkari.fi/bitstream/handle/10024/129581/Tr26 15.pdf

18. Ghotane SG, Al-Haboubi M, Kendall N, et al. Dentists with enhanced skills (Special Interest) in Endodontics: gatekeepers views in London. BMC Oral Health 2015;15:110 DOI $10.1186 / \mathrm{s} 12903-015-0085-8$

19. Dahlström L, Lindwall O, Rystedt H, et al. 'Working in the dark': Swedish general dental practitioners on the complexity of root canal treatment. Int Endod J 2016 Early View. doi:10.1111/iej.12675

20. The World Health Organization. Conceptual Framework for the International Classification for Patient Safety. WHO, 2009. WHO/IER/PSP/2010.2. http://www.who.int/patientsafety/taxonomy/icps_full_report.pdf

21. Pietikäinen E, Ruuhilehto K, Heikkilä J. [Learning from safety incidents]. Report VTT-R00414-10. 2010. Finnish, Summary in English. http://www.vtt.fi/files/projects/typorh/opas terveydenhuoltoorganisaatioiden vaaratapahtumista oppimiseksi.pdf 
22. Bailey E, Tickle M, Campbell S, et al. Systematic review of patient safety interventions in dentistry. BMC Oral Health 2015; 15:152. DOI 10.1186/s12903-015-0136-1

23. Kalenderian E, Walji MF, Tavares A, et al. An adverse event trigger tool in dentistry. A new methodology for measuring harm in the dental office. J Am Dent Assoc 2013;144:808-814.

24. Hiivala N, Mussalo-Rauhamaa H, Murtomaa H. Can patients detect hazardous dental practice? - A patient complaint study. Int. J. Health. Care Qual. Assur. 2015;28:274-287.

25. Renton T, Sabbah W. Review of never and serious events related to dentistry 2005-2014. Br Dent J 2016;221:71-79. DOI: 10.1038/sj.bdj.2016.526

26. Bjørndal L, Reit C. The adoption of new endodontic technology amongst Danish general dental practitioners. Int Endod J 2005; 38: 52-58.

27. Helminen SE, Vehkalahti M, Kerosuo E, et al. Quality evaluation of process of root canal treatments performed on young adults in Finnish public oral health service. J Dent 2000;28:227-232.

28. Helminen SE, Vehkalahti M, Murtomaa H, et al. Quality evaluation of oral health recordkeeping for Finnish young adults. Acta Odontol Scand 1998; 56:288-292.

29. Virtanen J, Swanljung O, Pöyry S, et al. [The dental injuries in the Finnish Patient Insurance Centre in 2000-2008]. J Soc Med 2010;47:244-249. Finnish, Abstract in English.

30. Koskinen S, Lundqvist A, Ristiluoma N, editors. [Health, functional capacity and welfare in Finland in 2011]. National Institute for Health and Welfare (THL), Report 68/2012. Helsinki 2012. Finnish, Abstract in English. https://www.julkari.fi/bitstream/handle/10024/90832/Rap068_2012_netti.pdf 


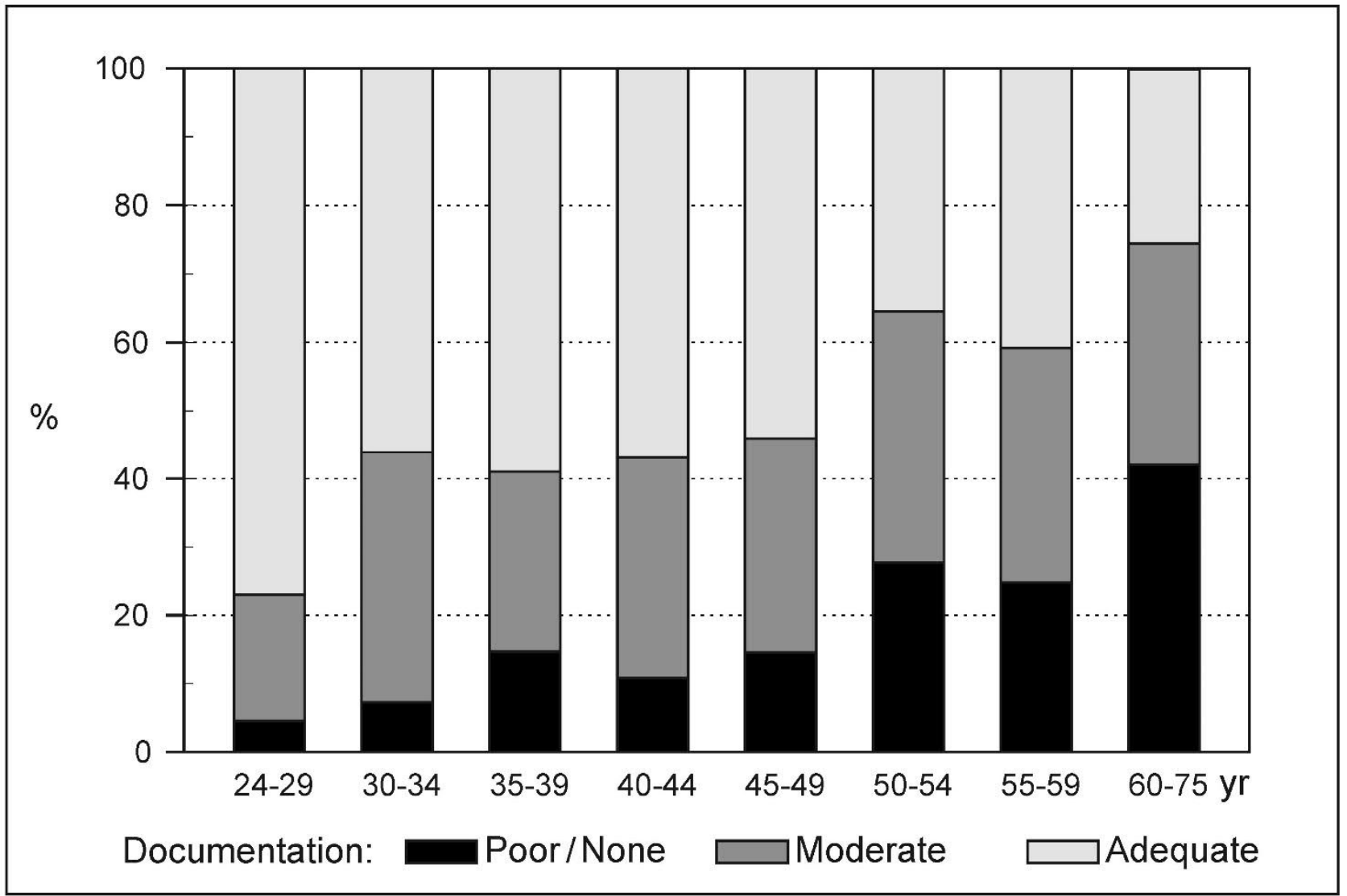

Figure 1. Quality of patient documentation in endodontic malpractice claims in Finland according to dentists' age. 
Table 1. Characteristics of the endodontic malpractice cases claimed to the Patient Insurance Centre in Finland, according to the service sector.

\begin{tabular}{|c|c|c|c|c|}
\hline Characteristics of cases & $\begin{array}{c}\text { All cases } \\
(n=1271)\end{array}$ & $\begin{array}{c}\text { Private sector } \\
(\mathrm{n}=680)\end{array}$ & $\begin{array}{l}\text { Public sector } \\
(n=591)\end{array}$ & pvalue \\
\hline \multicolumn{5}{|l|}{ Patients' age (years) } \\
\hline M ean (SD) & $44.7(14.4)$ & $46.1(13.6)$ & $43.2(15.0)$ & \multirow[t]{2}{*}{$\varangle 0.001$} \\
\hline Range; M edian & $8-85 ; 44.5$ & $16-82 ; 46.4$ & $8-85 ; 42.6$ & \\
\hline \multicolumn{5}{|l|}{ Patients' gender } \\
\hline Women (\%) & 71 & 70 & 73 & \multirow[t]{2}{*}{0.258} \\
\hline Men (\%) & 29 & 30 & 27 & \\
\hline \multicolumn{5}{|l|}{ Dentists' age (years) } \\
\hline M ean (SD) & $45.4(10.2)$ & $45.9(10.0)$ & $44.9(10.5)$ & \multirow{3}{*}{0.103} \\
\hline Range; M edian & $24-75 ; 45.5$ & $24-75 ; 45.7$ & $24-71 ; 45.4$ & \\
\hline Data missing & $\mathrm{n}=51$ & $n=13$ & & \\
\hline \multicolumn{5}{|l|}{ Dentists' gender } \\
\hline Women (\%) & 62 & 52 & 73 & \multirow[t]{3}{*}{$\varangle 0.001$} \\
\hline Men (\%) & 38 & 48 & 27 & \\
\hline Data missing & $n=6$ & $\mathrm{n}=1$ & $n=5$ & \\
\hline \multirow{2}{*}{$\begin{array}{r}\text { Dentists' professional level } \\
\text { General practitioner (\%) } \\
\text { Specialist (\%) }\end{array}$} & 93 & 91 & 96 & \multirow[t]{2}{*}{$\varangle 0.001$} \\
\hline & 7 & 9 & 4 & \\
\hline \multicolumn{5}{|l|}{ Type of tooth } \\
\hline Anterior (\%) & 12 & 11 & 13 & 0.090 \\
\hline Premolar (\%) & 23 & 21 & 25 & \\
\hline Molar (\%) & 65 & 68 & 62 & \\
\hline
\end{tabular}


Table 2. Process-related aspects in endodontic malpractice cases claimed to the Patient Insurance Centre in Finland, according to operators' background information.

\begin{tabular}{|c|c|c|c|c|c|c|c|c|c|c|}
\hline \multirow{2}{*}{$\begin{array}{l}\text { Aspects of process, based } \\
\text { on the information in the } \\
\text { patient documents }\end{array}$} & \multirow{2}{*}{$\begin{array}{c}\text { All claims } \\
\text { made } \\
(n=1271) \\
\%\end{array}$} & \multicolumn{2}{|c|}{ Service sector } & \multicolumn{2}{|c|}{ Dentist's gender } & \multicolumn{3}{|c|}{ Dentist's age (years) } & \multicolumn{2}{|c|}{ Dentist is specialized } \\
\hline & & $\begin{array}{c}\text { Private } \\
(\mathrm{n}=680) \\
\% \\
\end{array}$ & $\begin{array}{c}\text { Public } \\
(\mathrm{n}=591) \\
\%\end{array}$ & $\begin{array}{c}\text { Female } \\
(\mathrm{n}=781) \\
\% \\
\end{array}$ & $\begin{array}{c}\text { Male } \\
(n=484) \\
\% \\
\end{array}$ & $\begin{array}{c}24-39 \\
(n=373) \\
\% \\
\end{array}$ & $\begin{array}{c}40-49 \\
(n=402) \\
\%\end{array}$ & $\begin{array}{c}\mathbf{5 0 - 7 5} \\
(\mathrm{n}=445) \\
\% \\
\end{array}$ & $\begin{array}{c}\text { No } \\
(\mathrm{n}=1188) \\
\% \\
\end{array}$ & $\begin{array}{c}\text { Yes } \\
(\mathrm{n}=83) \\
\% \\
\end{array}$ \\
\hline \multicolumn{11}{|l|}{ Instrumentation } \\
\hline Manual & 61 & 60 & 63 & 61 & 57 & 57 & 66 & 64 & 62 & 51 \\
\hline Engine-driven & 31 & 31 & 30 & 28 & 34 & 34 & 30 & 26 & 30 & 41 \\
\hline Undocumented & 8 & 9 & 7 & 11 & 9 & 9 & 4 & 10 & 8 & 8 \\
\hline & & \multicolumn{2}{|c|}{$p=0.306$} & \multicolumn{2}{|c|}{$p=0.026$} & \multicolumn{3}{|c|}{$p=0.002$} & \multicolumn{2}{|c|}{$p=0.086$} \\
\hline \multirow{4}{*}{$\begin{array}{r}\text { Preoperative radiograph } \\
\text { Taken } \\
\text { Undocumented } \\
\end{array}$} & & & & & & & & & & \\
\hline & 62 & 63 & 61 & 63 & 61 & 64 & 58 & 63 & 62 & 65 \\
\hline & 38 & 37 & 39 & 37 & 39 & 36 & 42 & 37 & 38 & 35 \\
\hline & & \multicolumn{2}{|c|}{$p=0.460$} & \multicolumn{2}{|c|}{$p=0.604$} & \multicolumn{3}{|c|}{$p=0.218$} & \multicolumn{2}{|c|}{$p=0.562$} \\
\hline \multirow{5}{*}{$\begin{array}{r}\text { Apex location by } \\
\text { Working length radiograph } \\
\text { Electronic device } \\
\text { Undocumented }\end{array}$} & & & & & & & & & & \\
\hline & 43 & 40 & 46 & 45 & 39 & 45 & 46 & 39 & 44 & 37 \\
\hline & 20 & 21 & 20 & 22 & 18 & 21 & 23 & 16 & 19 & 35 \\
\hline & 37 & 39 & 34 & 33 & 43 & 34 & 31 & 45 & 37 & 28 \\
\hline & & \multicolumn{2}{|c|}{$p=0.107$} & \multicolumn{2}{|c|}{$p=0.003$} & \multicolumn{3}{|c|}{$p<0.001$} & \multicolumn{2}{|c|}{$p=0.002$} \\
\hline \multirow[t]{5}{*}{ Documentation } & & & & & & & & & & \\
\hline & 50 & 43 & 59 & 56 & 40 & 62 & 55 & 35 & 49 & 61 \\
\hline & 32 & 32 & 31 & 32 & 32 & 28 & 32 & 35 & 33 & 21 \\
\hline & 18 & 25 & 11 & 12 & 28 & 10 & 13 & 30 & 18 & 18 \\
\hline & & \multicolumn{2}{|c|}{$p<0.001$} & \multicolumn{2}{|c|}{$p<0.001$} & \multicolumn{3}{|c|}{$p<0.001$} & \multicolumn{2}{|c|}{$p=0.053$} \\
\hline
\end{tabular}


Table 3. Types of the injuries verified in endodontic malpractice cases claimed to the Patient Insurance Centre (PIC) in Finland, according to the operators' background information.

\begin{tabular}{|c|c|c|c|c|c|c|c|c|c|c|}
\hline \multirow{2}{*}{$\begin{array}{l}\text { Types of the injuries } \\
\text { verified when scrutinized } \\
\text { by the PIC dental advisors }\end{array}$} & \multirow{2}{*}{$\begin{array}{c}\text { All claims } \\
\text { made } \\
(n=1271) \\
\%\end{array}$} & \multicolumn{2}{|c|}{ Service sector } & \multicolumn{2}{|c|}{ Dentist's gender } & \multicolumn{3}{|c|}{ Dentist's age (years) } & \multicolumn{2}{|c|}{ Dentist is specialized } \\
\hline & & $\begin{array}{c}\text { Private } \\
(\mathrm{n}=680) \\
\%\end{array}$ & $\begin{array}{c}\text { Public } \\
(n=591) \\
\%\end{array}$ & $\begin{array}{c}\text { Female } \\
(\mathrm{n}=781) \\
\%\end{array}$ & $\begin{array}{c}\text { Male } \\
(n=484) \\
\%\end{array}$ & $\begin{array}{c}\text { 24-39 } \\
(\mathrm{n}=373) \\
\%\end{array}$ & $\begin{array}{c}\mathbf{4 0 - 4 9} \\
(n=402) \\
\%\end{array}$ & $\begin{array}{c}\mathbf{5 0 - 7 5} \\
(\mathrm{n}=445) \\
\%\end{array}$ & $\begin{array}{c}\text { No } \\
(\mathrm{n}=1188) \\
\%\end{array}$ & $\begin{array}{c}\text { Yes } \\
(n=83) \\
\%\end{array}$ \\
\hline Broken instrument & $\begin{array}{l}76 \\
24\end{array}$ & $\begin{array}{l}74 \\
26\end{array}$ & $\begin{array}{l}77 \\
24\end{array}$ & $\begin{array}{l}75 \\
25\end{array}$ & $\begin{array}{l}76 \\
24\end{array}$ & $\begin{array}{l}73 \\
27\end{array}$ & $\begin{array}{l}74 \\
26\end{array}$ & $\begin{array}{l}79 \\
21\end{array}$ & $\begin{array}{l}75 \\
25\end{array}$ & $\begin{array}{l}84 \\
16\end{array}$ \\
\hline & & \multicolumn{2}{|c|}{$p=0.231$} & \multicolumn{2}{|c|}{$p=0.764$} & \multicolumn{3}{|c|}{$p=0.106$} & \multicolumn{2}{|c|}{$p=0.056$} \\
\hline Perforation & $\begin{array}{l}78 \\
22\end{array}$ & $\begin{array}{l}80 \\
20\end{array}$ & $\begin{array}{l}76 \\
24\end{array}$ & $\begin{array}{l}78 \\
22\end{array}$ & $\begin{array}{l}77 \\
23\end{array}$ & $\begin{array}{l}76 \\
24\end{array}$ & $\begin{array}{l}79 \\
21\end{array}$ & $\begin{array}{l}78 \\
22\end{array}$ & $\begin{array}{l}78 \\
22\end{array}$ & $\begin{array}{l}78 \\
22\end{array}$ \\
\hline & & \multicolumn{2}{|c|}{$p=0.095$} & \multicolumn{2}{|c|}{$p=0.729$} & \multicolumn{3}{|c|}{$p=0.607$} & \multicolumn{2}{|c|}{$p=0.924$} \\
\hline $\begin{array}{ll}\text { Irrigant / Medicament } & \\
& \text { No } \\
\text { Yes }\end{array}$ & $\begin{array}{r}95 \\
5\end{array}$ & $\begin{array}{r}96 \\
4\end{array}$ & $\begin{array}{r}93 \\
7\end{array}$ & $\begin{array}{r}95 \\
5\end{array}$ & $\begin{array}{r}94 \\
6\end{array}$ & $\begin{array}{r}95 \\
5\end{array}$ & $\begin{array}{r}96 \\
4\end{array}$ & $\begin{array}{r}93 \\
7\end{array}$ & $\begin{array}{c}95 \\
5\end{array}$ & $\begin{array}{c}94 \\
6\end{array}$ \\
\hline & & \multicolumn{2}{|c|}{$p=0.066$} & \multicolumn{2}{|c|}{$p=0.359$} & \multicolumn{3}{|c|}{$p=0.180$} & \multicolumn{2}{|c|}{$p=0.831$} \\
\hline M iscellaneous & $\begin{array}{l}73 \\
27\end{array}$ & $\begin{array}{l}71 \\
29\end{array}$ & $\begin{array}{l}75 \\
25\end{array}$ & $\begin{array}{l}73 \\
27\end{array}$ & $\begin{array}{l}73 \\
27\end{array}$ & $\begin{array}{l}75 \\
25\end{array}$ & $\begin{array}{l}71 \\
29\end{array}$ & $\begin{array}{l}72 \\
28\end{array}$ & $\begin{array}{l}73 \\
27\end{array}$ & $\begin{array}{l}76 \\
24\end{array}$ \\
\hline & & \multicolumn{2}{|c|}{$p=0.060$} & \multicolumn{2}{|c|}{$p=0.872$} & \multicolumn{3}{|c|}{$p=0.387$} & \multicolumn{2}{|c|}{$p=0.508$} \\
\hline
\end{tabular}


Table 4. The role of operator-related factors in the occurrence of avoidable injuries in the endodontic malpractice cases ( $n=970)$, by means of logistic regression modeling. SE =standard error; OR =odds ratio; $95 \% \mathrm{Cl}=\mathrm{OR}$ 's $95 \%$ confidence interval; ref. =reference category.

\begin{tabular}{|l|c|c|c|c|c|}
\hline Parameter & Estimate & SE & OR & 95\%Cl & p value \\
\hline Service sector: Public (ref.), Private & -0.025 & 0.144 & 0.98 & $0.74,1.29$ & 0.863 \\
\hline Dentist's age (years) & 0.018 & 0.007 & 1.02 & $1.01,1.03$ & 0.007 \\
\hline Dentist's gender: Female (ref.), Male & 0.202 & 0.146 & 1.22 & $0.92,1.63$ & 0.168 \\
\hline Specialized: No (ref.), Yes & 0.014 & 0.304 & 1.01 & $0.56,1.84$ & 0.963 \\
\hline Patient's age (years) & -0.014 & 0.005 & 0.99 & $0.98,1.00$ & 0.005 \\
\hline Constant term & 0.144 & 0.467 & & & \\
\hline Fitting results: Deviance =1191.0; df =928 & & & & & \\
\hline
\end{tabular}

